\title{
Correction to: Venous Reflux Patterns
}

Sergio Gianesini, Paolo Zamboni, and Erika Mendoza

\section{Correction to:}

Chapter 3 in: P. Zamboni et al. (eds.), Saphenous Vein-Sparing Strategies in

Chronic Venous Disease, https://doi.org/10.1007/978-3-319-70638-2_3

In the original version of Chapter 3, part images $(\mathrm{a} \& \mathrm{~b})$ in figure 3.21 had been swapped and placed incorrectly in the proofs. The part images ( $\&$ b) have been corrected.

The updated online version of this chapter can be found at https://doi.org/10.1007/978-3-319-70638-2_3 